\title{
2 \\ Reconciliation, Trust and Liberal Inclusion
}

\section{Introduction}

Self-determination presumes the spirit and substance of reconciliation; it supposes trust and political inclusivity. Reconciliation provides a foundation for just terms of association. This foundation involves recognising injustice and taking steps to ensure that it does not recur. Reconciliation is neither simple nor uncontested. For some, it is a necessary condition for just political outcomes; for others, it is shallow symbolism; for others still, it does not propose measures of sufficient substance to transform political relationships in meaningful and far-reaching ways. For its proponents, reconciliation's underlying presumption is that, if the truth is known, and the perpetrators of injustice acknowledge that truth, then societies may correct the consequences of injustice and accept a different kind of politics.

The Declaration may contribute to reconciliation by providing principles to inform a politics of respect including respect for self-determination as a right that belongs to all and not just some. Reconciliation requires relationships of trust, and it requires that indigenous people can find reasons to trust political institutions and systems. Relationships of trust are preliminary to the noncolonial political order that the Declaration seeks. These relationships require that indigenous peoples have the political capacity to influence the cultures, values and operations of public institutions to reflect their own priorities and ways of working. Reconciliation requires substantive indigenous inclusion, participation and meaningful leadership in the policy process. 
Treaties are potential instruments of trust, and their contemporary discussion in Australia may draw the relationship between reconciliation and self-determination into public discourse. Conversely, exclusive policy measures, such as the Intervention, along with discriminatory welfare and education policies, position indigenous peoples as opponents in an 'us' and 'them' binary. Democratic exclusion is reconciliation's powerful opposite; it is a philosophy of fundamental political inequality that entrenches mistrust and in turn prevents effective public policy. Reconciliation shows how democratic exclusion can be contested.

\section{Reconciliation}

For indigenous politics, reconciliation is the idea that state sorrow and atonement for transgressions of justice provide the foundation for working out new, just and durable terms of association. Reconciliation requires 'awareness of the past, acknowledgement of the harm that has been inflicted, atonement for the causes, and action to change behaviour' (TRC, 2015, pp. 6-7). Although it is acknowledged that 'reconciliation will take some time' to realise (p. vi), the Declaration provides guidance on what reconciliation should achieve for indigenous peoples:

States shall provide effective mechanisms for prevention of, and redress for:

a. Any action which has the aim or effect of depriving them of their integrity as distinct peoples, or of their cultural values or ethnic identities;

b. Any action which has the aim or effect of dispossessing them of their lands, territories or resources;

c. Any form of forced population transfer which has the aim or effect of violating or undermining any of their rights;

d. Any form of forced assimilation or integration;

e. Any form of propaganda designed to promote or incite racial or ethnic discrimination directed against them. (UN, 2007b, art. 8[2])

Corntassel depicted the process as one of 'forgive and forget' (2012, p. 92).

While reconciliation is not a matter of 'shaming and pointing out wrongdoing' (TRC, 2015, p. vi), forgiveness cannot logically involve forgetting. Instead, the TRC focused on 'truth determination' to 'lay the foundation for the important question of reconciliation' (p. vi). 
For the commission, the 'important question' centred on the Indian residential school system established by the state: 'Now that we know about residential schools and their legacy, what do we do about it?' (p. vi).

Reconciliation means that the 'forgiven' party commits to restitutive measures and to relational justice in future encounters. It cannot simply preserve or legitimise the 'status quo', as Corntassel (2012) feared-nor can it occur without reparation nor restitution. Reparation is owed:

[when] one infringes on [another's] ... right to pursue and possess what he values ... [unfairly thwarts their] legitimate attempt to do or possess something ... [or] makes it impossible for [them] to pursue a legitimate goal, even if [they] never actually attempt to achieve that goal. (Boxill, 1995, p. 110)

From this perspective, the only argument that can be raised against reparation is that the alleged transgression was, in fact, just.

It is premature to accept Wiessner's (2008) argument that the Declaration is a 'milestone of re-empowerment' that may 'reverse colonialism' to make indigenous peoples 'sovereign again, masters of their own fate' (p. 1142). However, the Declaration is potentially an instrument of reconciliation and political clarity about self-determination and its possibilities (O'Sullivan, 2017). The TRC (2015) drew on the Declaration in its account of reconciliation, observing that:

[Reconciliation] requires that the paternalistic and racist foundations of the residential school system be rejected as the basis for an ongoing relationship ... It also requires an understanding that the most harmful aspects of residential schools have been the loss of pride and self-respect of Aboriginal people, and the lack of respect that non-Aboriginal people have been raised to have for their Aboriginal neighbours ... Virtually all aspects of Canadian society may need to be reconsidered. (p. vi)

The TRC was preceded by the Royal Commission on Aboriginal Peoples, which proposed reconciliation as a policy aspiration. The royal commission 'opened people's eyes and changed the conversation about the reality for the Aboriginal people in this country' (TRC, 2015, p. 7).

Similar roles were played in Australia by the 1987-1991 Royal Commission into Aboriginal Deaths in Custody and 1995-1997 National Inquiry into the Separation of Aboriginal and Torres Strait Islander Children from Their Families. Along with the 1992 Mabo and 1996 Wik Peoples v Queensland 
decisions of the High Court of Australia (see O'Sullivan, 2005), they contributed to the emergence of the 1990s as a decade of significant transformation in Indigenous public policy. The inquiry into the removal of Indigenous children was distinctive because of its recommendation that state, territory and federal parliaments make apologies for the removals (Human Rights and Equal Opportunity Commission, 1997). It focused public consciousness on Indigenous people's place within the national political community. Having played a role in the removals, Christian churches were vocal in their support for reconciliation. For them, secular reconciliation flowed from the concept's foundation in sacramental theology in which broken relationships between God and the penitent were corrected through sorrow, atonement and forgiveness, which was conditional on a demonstrated resolve to desist from further transgressions of justice. However, secular reconciliation's momentum was not sustained beyond the 1990s (O'Sullivan, 2005).

There was, for example, ideological resistance to public sorrow so that, while each of the state parliaments accepted the royal commission's recommendation to pass a motion of apology for the removals, the Commonwealth Parliament did not do the same until 2008. As Ian Anderson (2004) has argued, the Howard Government's (19962007) refusal to say 'sorry' reflected the wider contradictions of its indigenous policy:

Its disavowal of indigenous self-determination rested upon the denial of the ongoing existence of an indigenous polity. In part, this reflected an atomised understanding of society - indigenous people being preferably constructed as a population of individuals rather than socially organised, interconnected groups of families and clans. However, in setting indigenous health and social disadvantage as a policy priority, the neo-liberal state reconstituted the collectivity it sought to deny through the measurement of disadvantage and the development of institutional responses. (Ian Anderson, as cited in Mazel, 2016, p. 20)

The lesson for jurisdictions like Canada was that reconciliation requires a strong and unbreakable connection between sorrow and policy outcomes - between rhetoric and substance. Reconciliation needs to make people's lives better. It imagines significant political transformation, but it is a difficult and ongoing task grounded in relational justice. It is not clear or certain that one can ever say that society is forever 'reconciled'. However, as Newhouse (2016) put it in relation to Canada, reconciliation requires 
that 'we will have to confront our history, our governance processes and our understandings of Indigenous peoples and their capacity to govern themselves' (p. 2).

In Canada, the TRC recommended the establishment of an independent Reconciliation Council to report annually on policy consistency with reconciliation, providing a public record of the progress made towards implementing the commission's 94 'calls to action' to which the Canadian Government, led by Justin Trudeau (2015- ), had committed (Tasker, 2016). This commitment reflected a significant evolution in political thought from Pierre Trudeau's first government (1968-1979), which had sought to develop federal relationships with indigenous nations. From a Métis perspective, these efforts were attempts to recognise 'special needs' not 'special rights'. In 2003, the Canadian Supreme Court overturned that philosophical premise by recognising the Métis as a 'rights bearing people' (Métis Nation, 2017, p. 2) with protections under the Canadian Constitution.

While significant, the Supreme Court's decision remains distant from the Métis River Settlement's aspiration in 1869 to be recognised as a separate province in the Canadian federation. This 'dream for a self-governing Métis nation within the Canadian federation' has 'faded with time', but it has 'never died' (Métis Nation, 2017, p. 1). In 2015, as part of its election promise, Trudeau's Liberal Party of Canada observed that:

Canada must complete the unfinished work of Confederation by establishing a renewed Nation-to-Nation relationship with the Métis Nation, based on trust, respect and co-operation for mutual benefit. A Liberal government will work in partnership with the Métis Nation, on a Nation-to-Nation basis, to further Métis selfgovernment. (as cited in Métis Nation, 2017, p. 3)

Once in government, the Liberal Party affirmed its position, establishing a 'Permanent Bilateral Mechanism' with each of the First Nations, Inuit and Métis peoples. In 2017, the federal Minister of Justice and Attorney General, Jody Wilson-Raybauld, observed an important relationship between the Declaration and Canada's reconciliation efforts, both of which required 'a set of new laws, policies, institutions, structures and patterns of relationships that fit together and acknowledge and integrate Indigenous knowledge, perspectives and legal traditions' (Wilson-Raybauld, 2017). 
In 2015, Justin Trudeau told the national Assembly of First Nations that:

It is time for a renewed nation-to-nation relationship with First Nations Peoples.

One that understands that the constitutionally guaranteed rights of First Nations in Canada are not an inconvenience but rather a sacred obligation. (Trudeau, 2015, paras. 23-24)

Nation-to-nation relationships recognise indigeneity's political distinctiveness. They establish nationhood-rather than race, ethnic minority status or relative material poverty —as differentiation's purpose and justification. In response to Trudeau, the assembly's national chief, Percy Bellegarde (as cited in Sweetgrass, 2015), remarked:

We are being heard and I believe understood like never before.

We are opening doors in Ottawa to facilitate the work of all First Nations, on the implementation and recognition of our rights and title, treaty enforcement and implementation, and realizing selfdetermination for Indigenous Nations. (paras. 14-15)

Fitzgerald and Schwartz (2017) observed that Canada may indeed 'be on a path toward reconciliation with Indigenous peoples' (p. 1). If so, engagement with the Declaration represented 'an opportunity to explore and reconceive the relationship between international law, indigenous peoples' own laws and Canada's constitutional narratives' (p. 1). This engagement required a reappraisal of political relationships, such as the federal parliament's retention of jurisdiction over 'Indians and lands reserved for Indians' (UN, 2014, p. 6). For example, indigenous jurisdiction over social policy, especially the care and protection of children, competes with state assumptions of knowing better, state control of public budgets and the hegemonic value to the state of positioning indigenous peoples as deficient in the care and safety of their children. The Canadian Indian Act 1876, a powerful symbol of the 'we know best' position, remains an obstacle to reconciliation and thus self-determination (Wilson-Raybauld, 2017).

The Indian Act was intended to 'civilise' the indigenous populations. In 2014, the UN Special Rapporteur on the Rights of Indigenous Peoples recorded a series of human rights violations under the Act: 'A rigidly paternalistic law at its inception, it continues to structure important aspects of Canada's relationship with First Nations today, although efforts 
at reform have slowly taken place' (UN, 2014, p. 4). Referencing this paternalism, it is significant that the National Aboriginal Economic Development Board proposed that, in constructing nation-to-nation relationships, the Canadian Government refrain from a 'we know best' approach to policy development (Public Policy Forum, 2017).

Reconciliation's ability to eliminate the marginal political status of indigenous people relies on substantive indigenous participation, yet the TRC (2015) only recommended 'consultation':

We call upon federal, provincial, territorial, and municipal governments to fully adopt and implement the United Nations Declaration on the Rights of Indigenous Peoples as the framework for reconciliation. (p. 325)

We call upon the Government of Canada to develop a national action plan, strategies, and other concrete measures to achieve the goals of the United Nations Declaration on the Rights of Indigenous Peoples. (p. 325)

We call upon the Government of Canada, on behalf of all Canadians, to jointly develop with Aboriginal peoples a Royal Proclamation of Reconciliation to be issued by the Crown. The proclamation would build on the Royal Proclamation of 1763 and the Treaty of Niagara of 1764, and reaffirm the nation-tonation relationship between Aboriginal peoples and the Crown. The proclamation would include, but not be limited to, the following commitments:

i. Repudiate concepts used to justify European sovereignty over Indigenous lands and peoples such as the Doctrine of Discovery and terra nullius.

ii. Adopt and implement the United Nations Declaration on the Rights of Indigenous Peoples as the framework for reconciliation.

iii. Renew or establish Treaty relationships based on principles of mutual recognition, mutual respect, and shared responsibility for maintaining those relationships into the future.

iv. Reconcile Aboriginal and Crown constitutional and legal orders to ensure that Aboriginal peoples are full partners in Confederation, including the recognition and integration of Indigenous laws and legal traditions in negotiation and implementation processes involving Treaties, land claims, and other constructive agreements. (p. 199) 
Reconciliation requires just terms of association in every field of public life. The commission was 'convinced that [the Declaration] ... provide[d] the necessary principles, norms, and standards for reconciliation to flourish in twenty-first-century Canada' (TRC, 2015, p. 21). Further, the commission proposed that public institutions should operate in ways that are consistent with the Declaration, 'which Canada has endorsed' (p. 21).

Reconciliation is yet to do for Australia what the TRC urges for Canadathat is, inspire Aboriginal and non-Aboriginal peoples to transform Canadian society ... [to] live together in dignity, peace, and prosperity on these lands we now share' (TRC, 2015, p. 8), which requires trust grounded in inclusive and respectful political relationships.

\section{Trust and the Politics of Inclusion}

As well as providing a foundation for just terms of association, reconciliation's purpose is to bring trust to political relationships. Procedural integrity is preliminary to just policy outcomes. Truth is important-not simply truth about the content of a given policy proposal but a deeper truth about the history that lies beneath political relationships. Reconciliation requires that parties accept the other's legitimacy, its right to be present in the body politic in its own way and for purposes that might differ from one's own.

Relationships of trust are difficult to achieve, though as determinants of a noncolonial political order, they are vitally important. As one nonaboriginal witness to the TRC (2015) explained:

I really understand the reticence of some First Nations people about wanting to accept offers of friendship and possibilities of interaction. I understand why that is and I hope that in time we will be able to gain trust and some kind ways of interacting with one another that will be mutually beneficial. ... I think we're moving. ... I think civil society, non-governmental organizations, church organizations, Aboriginal organizations are moving in the direction of openness ... and I think we have a long way to go. (quotation is as it appears in the source, p. 308) 
Trust presumes substantive indigenous inclusion in decision-making. However, Canada is yet to develop processes to ensure that inclusion in national citizenship.

Citizenship and self-determination are not only bodies of rights but also the assurance of political capacity. For example, it is important to be present when decisions are made about the policy settings and budgetary allocations that influence self-determining opportunities. An indigenous presence in public institutions 'indigenises' the bureaucracy (Maaka \& Fleras, 2009) by allowing indigenous people to participate at all levels of the policy process: from the executive to the legislative, and from the school to the police station. It allows indigenous people to be involved in setting, implementing and evaluating policy priorities. Indigenous presence reduces the political gap between decision-makers and those who experience those decisions when they engage with public institutions. Trust is an essential precursor to legitimacy.

The long history of indigenous mistrust of government has many explanatory variables - for example, the practice of approving development projects on indigenous lands against a community's wishes. Beck's (2016) comparison of the approaches to water management consultation of the governments of Alberta and the Northwest Territories in the Mackenzie River Basin highlighted the differences between Alberta's minimalist approach to engagement and the Northwest Territories' more participatory approach, and emphasised the 'important implications for moving [free, prior and informed consent to development] from an international norm to a domestic template for action in Canada' (p. 487). Beck's study serves as an example of von der Porten, Lepofsky, McGregor and Silver's (2016) claim that, in Canada:

The time of Indigenous 'inclusion' into state-led marine policy making is ending. Indigenous peoples are increasingly asserting their rights to primary roles in policy- and decision-making that affect the traditional homelands, freshwater bodies and oceans. (p. 68)

Participation implies serious and secure opportunities for indigenous peoples to influence the outcome of negotiations and supports reconciliation by providing reasons for trust.

Creating reasons for trust motivates contemporary Australian debates about treaties and an Indigenous voice to parliament. In 2019, the Victorian and Northern Territory governments engaged in treaty 
negotiations with Indigenous nations, and the New South Wales Opposition (the Labor Party) indicated that it would do the same if it was able to form government after that state's next election. ${ }^{1}$

One would expect such treaties to recognise prior Indigenous occupancy of Australia and to accept that this provides grounds for at least some degree of Indigenous intranational self-determination. In return, the state may expect recognition of its own legitimacy. The question for the Indigenous nations is whether and to what extent this is reasonable, and, if it is not reasonable, the points on which the state should concede to create moral legitimacy. Part of the difficulty is that there is no precedent for a treaty or treaties in Australia. Canada's modern treaties and New Zealand's Treaty of Waitangi were signed in such different contexts that the guidance they could provide may be limited.

Modern Canadian treaties are settlements of land claims not otherwise able to be settled. In 2014, 24 modern treaties affecting 95 indigenous communities and 40 per cent of the Canadian landmass were in place (UN, 2014). However, according to the UN special rapporteur, the conclusion of land settlement agreements appeared to have occurred in a confrontational context in which the government perceived 'the overall interests of Canadians as adverse to aboriginal interests, rather than encompassing them' (UN, 2014, p. 16).

Whereas in New Zealand the Treaty of Waitangi was signed before colonisation commenced, the Australian treaties are proposed more than 200 years after the event. Treaty policy is well developed in New Zealand but not fully settled. The UN Committee on the Elimination of Racial Discrimination (2007) suggested that New Zealand 'continue the public discussion over the status of the Treaty of Waitangi, with a view to its entrenchment as a constitutional norm' (para. 13).

In 2017, the New South Wales Aboriginal Land Council argued that a treaty was needed to 'codify and provide certainty about the relationship between the State Government and Aboriginal peoples' (para. 4). The council expected such a treaty to support 'five key goals - protecting our culture and heritage, pursuing our full Land and Water rights, driving economic independence and prosperity, supporting our peoples and

1 At the 2019 state election, the Liberal and National Party coalition government was returned and had no stated interest in pursuing treaties. 
securing our future' (New South Wales Aboriginal Land Council, 2017, para. 8). While in Australia, official interest in addressing disadvantage has strengthened since the Howard Government's defeat in 2007, this interest has been principally one of egalitarian justice rather than substantive self-determination justifying any redistribution of political authority, such as that which a treaty might secure.

Any trust generated from these egalitarian concerns is inevitably compromised by Australia's otherwise poor record of achievement and inattention to the recognition of meaningful indigenous political authority. In 2017, the UN Permanent Forum on Indigenous Issues could cite only three instances of policy success from the Council of Australian Governments' Closing the Gap in Indigenous Disadvantage policy: ${ }^{2}$ a decline in child mortality rates, an increase in final year secondary school completion rates and a reduction in mortality from chronic diseases (UN, 2017a, p. 2).

The requirement that the prime minister report annually to parliament on progress towards Closing the Gap policy targets ensures that there is at least scope for public accountability, which the UN special rapporteur argued ought to be complemented by a systematic process for Indigenous people themselves to monitor progress (UN, 2017b). In 2018, this principle was recognised in a small though potentially significant way with the appointment of the first Indigenous Commissioner to the Productivity Commission. The commissioner's duty is to lead Indigenous evaluations of Closing the Gap. Indigenous-led policy evaluation may help to close the relational gap between Indigenous peoples and the policy process. It may also help to raise Indigenous trust and confidence in the intent of public policy.

Closing the gap in political disadvantage is also important. Calls for a constitutionally guaranteed Indigenous voice to the national parliament reflect the argument that democratic institutions ought to hold indigenous peoples' confidence. Trust and confidence cannot be assured unless it is apparent to indigenous peoples that their values have the capacity to

2 Closing the Gap is a policy measure of the Council of Australian Governments. It aims to close statistically measurable gaps in Indigenous disadvantage in areas such as health and education. It has been largely unsuccessful and critiqued for not sufficiently including Indigenous people and perspectives in its development. Governments have, in part, tried to address these critiques. The policy contrasts with the more holistic and inclusive approach to disadvantage in civil society's Close the Gap policy approach; see O'Sullivan (2015) for an account of the distinctions between the two. 
influence and that their citizenship is meaningful. This contrasts markedly with the approach taken by the Howard Government in 2007, which explicitly excluded Indigenous consultation in drafting the Intervention. The Intervention used the military to 'restore order' after an official report identified high levels of child sexual abuse across Indigenous communities in the Northern Territory (Northern Territory Government, 2007). Its stated purpose was to address a 'crisis of community dysfunction' (Explanatory Memorandum, Northern Territory Emergency Response Bill 2007 [Cth], pt. 8 para. 14) and human rights obligations in respect of child safety.

The sense of injustice that the Intervention raised among many Indigenous people was grounded in the long history of public indifference towards the sexual violation of Indigenous women by white men. In its review of this history, the Human Rights and Equal Opportunity Commission (1997) demonstrated the striking hypocrisy of the Intervention for Indigenous people whose:

removal as children and the abuse they experienced at the hands of the authorities or their delegates have permanently scarred their lives. The harm continues in later generations, affecting their children and grandchildren. (p. 4)

The Intervention required suspension of the Racial Discrimination Act 1975 (Cth), which meant that:

Persons subject to the Northern Territory Intervention are
prevented from challenging, on the basis of racial discrimination,
its measures through existing domestic law and are prevented from
seeking any remedy. (Merkel, Newhouse \& Schokman, 2009,
para. 266)

Significantly, there were no Indigenous members of the Australian House of Representatives at the time the legislation was passed. In setting aside self-determination's essential presumptions - that is, 'the rights to freedom from discrimination and participation in decision-making' (Cowan, 2013, p. 280) — the power of democratic exclusion was clear.

Differentiated liberal citizenship may have prevented the Intervention by preventing the states presumption of absolute power. Instead, the Intervention further diminished Indigenous citizenship. For example, welfare payments were sequestered and the Intervention became the catalyst for the trial of a cashless welfare card in the Northern Territory and 
other largely Indigenous parts of Australia. Under the trial, a proportion of a beneficiary's payment from the state was placed on to a bank card that could not be used to purchase alcohol or tobacco. In this way, some but not all citizens' capacity to make their own spending decisions was removed. The racial make-up of a community was the criterion for inclusion in the trial.

The cashless welfare card trial showed that an obstacle to Indigenous policy development was the quality, and sometimes even the presence, of valid evaluative data. For example, a government report proclaiming the trial's success was not independent and appeared to have been written to support a predetermined outcome. Clarke (as cited in Davey, 2017) explained that:

Surprisingly there is no use of statistical methods to test the significance of any observable trends, so it's hard to know what can be concluded even on a descriptive level ... Given the issues with the design, it is difficult to see how they will have evidence of the program's impact on which to base an informed policy decision. (para. 27)

Despite extensive community consultation during the scheme's development and review, the then Minister for Human Services overstated the case in claiming consultation as 'an element likely contributing to its early success' (Tudge, as cited in Davey, 2017, para. 32). Indigenous opinion was divided. However, consensus on future policy proposals is more likely to emerge if all concerned have access to the same robust and reliable evaluative data, and time and space to deliberate. The appointment of the Indigenous Productivity Commissioner is a step in that direction.

\section{Mistrust and Policy Racism}

The UN special rapporteur has described the legacy of Indigenous Australian marginalisation as a subtle form of racism (UN, 2017b). The failure to recognise the historical and ongoing significance of this legacy has had a compounding effect. In this context, the Intervention was not only an explicit defence of racial discrimination and justification of political inequality but also helped to explain why some Aboriginal people feel that they 'are born with one foot in the grave' (Axelby \& Wanganeen, 2017, para. 10). 
One cannot reduce sexual, drug and alcohol abuse, violence and/or parental neglect to a unidimensional explanation grounded in individual moral weakness (Collingwood-Whittick, 2012). Nor is it useful to examine more complex and multifaceted explanations unless they add to what is already known about likely solutions. Especially as indigenous mistrust of the state obstructs effective policymaking, the key is to identify institutional arrangements and values that lend themselves to the implementation of known solutions. As Canada's TRC and Australia's Inquiry into the Separation of Aboriginal and Torres Strait Islander Children from Their Families show, schools, hospitals and welfare agencies have been used systematically and deliberately to undermine indigenous societies. This history continues to interfere with the development of indigenous respect for the state and confidence in the honour of its intentions. Given this context, the UN special rapporteur recommended that Australia's Closing the Gap policy targets be extended to include reductions in the rates of imprisonment, child removal and violence against women (UN, 2017b). He had earlier expressed the view that Aboriginal peoples' concerns merited 'higher priority at all levels and within all branches of government' (UN, 2014, p. 20).

Mistrust contributes to poor outcomes in education and health. In Australia, Indigenous people discharge themselves from hospital against medical advice at 13 times the rate of other citizens (Australian Institute of Health and Welfare, 2009) and many Indigenous children find school unsatisfactory-mistrust helps to explain why. Lee, Fasoli, Ford, Stephenson and McInerne (2014) explained that 'We should not be surprised if even very young children find school learning programs so unrewarding they sometimes decide to stay away' (p. 231).

Mistrust arises from decisions like the one to reduce bilingual schooling in the Northern Territory in 2008. The policy was in response to poor results in national school assessments. Blame was apportioned to the children themselves and to the bilingual nature of their schooling, yet there were (and are) remote schools in the Northern Territory that did not have a resident teacher (Lee et al., 2014). It is likely that the decision to reduce bilingual schooling was ideologically inspired, as only 20 per cent of the Northern Territory's children were schooled in bilingual programs. Further variables contributing to low achievement were not properly considered, nor was the Australian state's proper contribution to indigenous language retention as a matter of relational justice brought into account (Lee et al., 2014). This oversight was especially striking in 
light of the UN Permanent Forum on Indigenous Issues's proposal for an International Year of Indigenous Languages to draw political attention to language preservation and revitalisation as a matter of urgency for many indigenous peoples (Pop Ac, 2017).

It is inaccurate for school pedagogies to presume that English is the indigenous child's first or dominant language. Standard English is not the principal means of communication for most Indigenous children in the Northern Territory, and English needs to be taught as an additional language (Lee et al., 2014). Although standard English is a prerequisite for entry into the middle class, in which access to political authority disproportionately lies, it cannot, efficaciously, be the school system's only language. Nor, as a matter of justice, can it alone define the knowledge that the system legitimises. According to Devlin (2009), 'there is a deeper meaning' to bilingual schooling, as:

a tool for survival in a fast changing, often confusing world. It can open up new, inspiring perspectives as learners from one culture come to grips with the metaphors, the core concepts, the key insights, the poetry, the art and music of the other culture. (p. 3)

Language is the means through which culture is expressed and developed, and the means through which relationships and environments are understood. Languages are basic rights of humanity. The undermining of indigenous languages by the state is a routine colonial strategy.

Signalling institutional racism, Lee et al. (2014) observed that, in Australia, teacher training programs are not responsive to the linguistic context of classrooms that require Indigenous children to learn in a language in which they are not proficient. They argue that Indigenous children are not presented with the same opportunity to learn as non-native English-speaking migrant children for whom additional English language instruction is available, yet the Declaration requires that schooling give all citizens equal opportunity. Citizenship requires that school systems aim to give all school leavers the capacity for social participation.

In Australia, Year 12 completion rates are improving (Belot \& Laurence, 2017). Closing the gap in Year 12 completion rates is arguably the most important of the seven Closing the Gap targets, as failure against all others is ultimately a function of poor education; yet, and often explicitly, educational success has not been the system's aspiration for indigenous peoples. Schooling for indigenous peoples exists in a political and cultural 
context that distinguishes it from schooling for other citizens. Public schooling's role in the usurpation of indigenous political authority and its cooption by the state as a coercive force in the assimilation of indigenous peoples gives it a morally, as well as politically, important contemporary role in reconciliation by contributing to the restoration and maintenance of self-determination.

Self-determination requires that public schools adopt a 'culturally sustaining pedagogy' (McCarty \& Lee, 2014, p. 101). This has particular relevance in the US, where almost 90 per cent of Native American children attend public schools despite the existence of private charter schools (McCarty \& Lee, 2014). Although their success is mixed, American charter schools are intended to support indigenous peoples' authority to make decisions about their children's education (McCarty \& Lee, 2014). This philosophical presumption, which is absent in the Australian system, might help to increase indigenous people's trust and confidence in the education system as one that exists for them as much as for anyone else.

The Native American Community Academy in Albuquerque, New Mexico, is more successful than public schools in terms of student retention and achievement (McCarty \& Lee, 2014). It has a curriculum based on 'respect, responsibility, community/service, culture, perseverance and reflection' (McCarty \& Lee, 2014, p. 108). The school privileges relationships in ways that are not possible in mainstream public schools. As one teacher explained to McCarty and Lee (2014):

The relationship that we're gonna have in this classroom-I'm gonna treat you like one of my nieces or nephews, so that it does not end once we are out of this class. It does not end once you've graduated from [Native American Community Academy]. (p. 109)

Relationships within schools, and between schools and their communities, are important determinants of scholastic achievement (Bishop et al., 2010). Schooling ought to enhance and secure cultural identity. It should also help to increase indigenous access to the middle class, for that is where economic security and the capacity to deliberate in public affairs is disproportionately found. Effective schooling is also important for realising the demographic dividends that indigenous population structures in Australia, Canada, New Zealand and the US allow. 
Demographic dividends are the opportunities that arise from a youthful population structure. As Jackson (2011) explained, the differential in Maori educational attainment may decline 'simply because' a disproportionate number of Maori are of an age at which qualifications are most likely to be completed. The median age of Maori is 15 years lower than the median age for non-Maori people. Maori aged 15-24 years comprise 31 per cent of the Maori working age population (Jackson, 2011), which, on its own, ought to contribute to a reduction in the income differential as this cohort's income rises with age and experience. At the same time, participation rates for secondary schooling and university enrolments among Maori have increased. Between 2008 and 2017, the rate of university enrolment for Maori increased by 16 per cent, and postgraduate enrolments for Maori increased by 19 per cent (Universities New Zealand, 2018). Contributing factors included an increase in the number of Maori attaining the required school level qualifications for entry to university, the Maori age structure and increasing financial support from iwi (tribes) to their members.

Almost half the indigenous Canadian population is under the age of 25 years. This creates opportunities of the kind and scope that Jackson (2011) imagined for New Zealand, in which the importance of recognising and proactively investing in the dividend years for Maori ... to transform them to economic windfalls cannot be overemphasised' (p. 70). Similarly, from 1991 to 2016 in Australia, the number of Indigenous university graduates increased from fewer than 4,000 to 30,000 (Grant, 2016), creating scope for a significant demographic dividend. However, demographic dividends do not always extend to economic dividends (Jackson, 2011). This requires deliberate policy measures and systematic indigenous-led policymaking to eliminate mistrust as an obstacle to effective education, for example, and which an Indigenous voice to parliament would facilitate. Indigenous-led policy evaluation to inform policy development is similarly important and is the outcome that the appointment of an Indigenous Productivity Commissioner is intended to facilitate.

As the UN special rapporteur has recommended, policy processes ought to 'value and prioritise the [policy] leadership of Aboriginal and Torres Strait Islander people' (UN, 2017b, Closing the Gap and health, para. 4). This is fundamental to the trust that reconciliation requires and is an example of the participation in public affairs that self-determination requires. 


\section{Conclusion}

The Declaration 'offers a positive framework for state-indigenous relations, but much more theoretical and political work remains' (Maciel, 2014, p. 39). This book's purpose is to contribute to a theoretical account of what the Declaration might mean for the conduct of contemporary indigenous-state relations and for securing indigenous belonging to the state. Reconciliation, trust and inclusivity are essential to that discussion. As it is for the Declaration itself, reconciliation's ultimate test is its capacity to contribute to a democratic form that raises indigenous quality of life and political authority.

For reconciliation to occur, indigenous people must find reason to accept that the postsettler state is at least capable of legitimacy. Equally, the act of reconciliation must be of sufficient substance to make the state worthy of trust-for without trust, self-determination is impossible.

Trust may follow if the Declaration is engaged to show how indigenous rights are not just acceptable in liberal theory but also required. In this regard, the Declaration's overarching potential is to rationalise a liberal theory of indigeneity that may, for some indigenous peoples, give moral integrity to the modern state. However, trust is difficult partly because state acceptance of the Declaration by Australia, Canada, New Zealand and the US is reluctant and conditional.

The following chapter discusses Australian, Canadian, New Zealand and US perspectives on the Declaration; their shifts from opposition to acceptance of its value as an 'aspirational' document; and liberal theory's capacity to support both indigenous inclusion and exclusion. 
This text is taken from 'We Are All Here to Stay': Citizenship, Sovereignty and the UN Declaration on the Rights of Indigenous Peoples, by Dominic O'Sullivan, published 2020 by ANU Press, The Australian National University, Canberra, Australia.

doi.org/10.22459/WAAHTS.2020.02 